\title{
Alcohol Consumption Behaviour among Secondary School Students in Nigeria
}

\author{
Dr. F.O Bada1
}

Adebiyi, D.R ${ }^{2}$

\author{
1,2Department of Guidance and Counselling, Faculty of Education, Ekiti State University, Nigeria
} Sampromise2@gmail.com¹, adamilolaruth7@gmail.com²

\author{
Doi:10.5901/jesr.2014.v4n3p507
}

\section{Abstract}

The prevalence of alcohol consumption among teenagers and especially those at secondary school level has led to a number of societal anomalies such as decline in students' academic performance, violence and various forms of anti-social behaviour. These led to the birth of this study geared to know the factors that facilitate alcohol drinking and also to know if there is difference in the behaviour of male and female after consumption of alcohol. The study employed a descriptive research of survey type .The research instrument was titled "Alcohol consumption Questionnaire". The face and content validity was ascertained by Psychologist and Guidance and counselling experts. A reliability coefficient of 0.85 was obtained using split half method. The population consist of all students in Ado-Local government. One hundred and forty samples were selected through stratified and simple random sampling techniques. The finding revealed that family background and religion were strong correlates of alcohol consumption among secondary school students. Again, it was found out at that the family should take appropriate measures in curbing their children also that religious bodies approach the issues of alcoholism with more firm measures.

Keyword: Family Background, Religion and Anti-Social, Alcohol Consumption

\section{Introduction}

Alcohol consumption appears very rampant in schools and in the society at large. It seems to be the source one of the country's major health challenge as well as social problems. The impact of alcoholism on youth has remained a source of worry to parents, schools, society and even the government because of the attendant misbehaviours that usually follow it have negative effect on the society and educational advancement cum achievement of the students.

Current trends suggest that overall drug use is on the decline, but the proportion of youth continuing to initiate illicit substance use remains troubling. According to a recent survey, youth perception of harm associated with illicit substance use (e.g., marijuana) remains low, whereas abuse of inhalants is at a recent all-time high (Johnston et al., 2005). In 2004, approximately 1.4 million adolescents reported past year methamphetamine use (SAMHSA, 2005), and nearly 2.1 million youth across the United States engaged in marijuana use for the first time (Johnston et al., 2005).As a result of these trends, researchers increasingly have targeted adolescent substance users.

There are various locations where students have access to alcohol such as beer parlours, clubs, parties and so on. It has been observed that people across cultures and countries have different reasons for drinking alcohol. Some people drink in other to conform to the norm of a particular group while adolescents majorly engage in alcohol drinking for ego assertion birth as a result of desire to be independent. For other adolescents they engage in drinking in other to reduce frustration, relieve boredom, fatigue and in addition they perceive that it could help them to escape harsh realities of their world. Some youths intake of alcohol is influenced by their parents, personal gratification and temporary adaptations are also reasons while young adults venture into alcohol consumption which is usually festered by family background crisis such as divorce or separation. Hence, such young adults are exposed and lack significant adults in their life to check their socially undesirable behaviours.

Several scholars and researchers has attributed alcohol consumption to a lot of reasons and factors. World Health Organization (2004), posited that alcohol consumption are usually due to environmental factors, friends or peer group, social wellbeing and uncontrollable drinking habits of an individual. Again it is not uncommon to find students consume alcohol because of curiosity, urge and desire to achieve success in a competitive world, emotional disturbances such as anxiety due to stress, subculture and advertisement influence. Bennett (1997) viewed alcohol as a drink that is as dangerous as cocaine and heroin. He went further to note that the unfortunate thing about it is that, unlike other similarly 
dangerous drugs, it appears to enjoy greater acceptance and its consumption is often openly applauded by the government, press and manufacturers. This could be as a result of the resources which the government in form of tax receive and higher sales made from it. It is noticed that even at the periods of economic depression ; breweries continue to record and declare heavy profits and parts of which also goes into expansion of the production plants.

WHO(2004), stated the side effect of alcohol on individuals and society at large. These effects are numerous and include the following; psychological disorder, untimely death and health problems to mention in summary. Regardless of these negative effects, Nigerians celebrate every joyful occasion with alcoholic drinks; be it naming ceremonies, birthday parties, promotions and even burial ceremonies.

All these are factors that enhance the consumption of alcoholic substance by adolescents. Johnson and Johnson (2000) identified some of the factors further such as dysfunctional families, cheap availability of alcohol, hereditary, gender, race, and ethnicity. According to Quine and Stephenson (1990) posited that the attitude of parents towards alcohol will also affect how children will feel about the depressant. Invariably many students who consume alcohol are from families where there low levels of parenting and emotional support and also a lack of control and monitoring of a child's behaviour, poor family communication, inadequate family problem, solving and nagging at home. In which case, an individual's family background plays an important role in the attitude of students' alcoholism.

Religious affiliation has also been found as an important factor that determines alcohol consumption among students. It is usually believed that religious groups have rules, ethics and guidelines that guide them. Most religion advocate mediation in all things, this principle could hence be transferred to the issue of alcohol consumption. In this study conducted by Jenkins (2013), he found out that religiously affiliated students reported less alcohol consumption than the non religion students. In a survey carried out in Ibadan, religion was found to have a significant relationship with a significant relationship with alcohol consumption(Adenuga\&ijagbone,2012).

Young people join different peer groups and identify themselves with these groups by participating in their activities so as not to be rejected. According to Mello(1996) he found out that alcohol consumption among students is on the increase and that they are mostly influenced to drinking alcohol by their friends and these on the other affect attitude towards school. A young person who is attached to a peer group that values anti social activities inevitably finds it difficult to resist the encouragement of peer group members in such negative behaviour. Environmental influences on alcohol includes acceptance of alcohol use by the society, through mass media, role models and this acceptance is demonstrated by lack of formal laws enforcement and social disapproval for those who engage in dangerous drinking or create problems while drunk. This has a way of sending messages to the younger generation that such behaviour is accepted; as it intoxicates behaviours (including assaults, vandalism and public nuisance).

\section{Purpose of the Study}

The purpose of this study is to investigate the influence of family background and religion on alcohol consumption behaviour among secondary school students. It will also investigate the influence of religion and the behavioural pattern exhibited by male and female students after alcohol consumption.

\section{Research Hypotheses}

Two research hypotheses were generated and tested.

1. There is no significant difference between students' from polygamous and monogamous homes and alcohol consumption.

2. There is no significant difference between students' religion and alcohol consumption

3. There is no significant difference between students' from single parenting homes and those living with both parents and their alcohol consumption

\section{Method}

This study employed descriptive research design of the survey type. The sample consisted of one hundred and forty(140)students which were selected with the use of stratified and random sampling technique from (4) secondary schools in Ado Local government of Ekiti State.

A self constructed research instrument titled "Alcohol consumption Behaviour Questionnaire" was use. It had two section; the first part consist of respondents personal data and the section B was subdivided into four parts that contains 
statements measuring religion, environmental influences and family background.

A Likert scale of 1 to 4 of Strongly Agree, Agree, Disagree, Strongly Disagree was used in measuring responses of the respondents. The content and face validity of the instrument was ascertained by experts in psychology and Guidance and Counselling. The reliability of this instrument was obtained with use of split-half method. A reliability co-efficient of 0.85 was obtained. Data collected were analyzed with inferential statistics. Students t-test was used to the test hypotheses. All hypotheses were tested at 0.05 level of significance.

\section{Results}

5.1 Hypothesis1: There is no significant difference between students' environmental influences and their environmental influences and their environmental consumption.

Table 1: T-test showing alcohol consumption between students from polygamous home and their monogamous home.

\begin{tabular}{|l|c|c|c|c|c|c|}
\hline Variables & $\mathrm{N}$ & Mean & SD & DF & t-cal & t-crit \\
\hline Students from polygamous home & 100 & 48.0 & 43.2 & 138 & 9.803 & 2.02 \\
\hline Students from monogamous home & 40 & 5.28 & 3.66 & & & \\
\hline
\end{tabular}

Table 1 shows that the mean of variables (monogamous and polygamous) as 48.0 and 5.28 respectively. It is clear that students from polygamous home with the mean of 48.0 will be highly exposed to alcoholic drinks probably due to lack of proper parental care as compared with their counterparts from the mean of 5.28 . The value of the t-calculated (9.80) and the t-critical as (2.02), this therefore evidently shows that $t$-calculated is greater than $\mathrm{t}$-table value. This hypothesis is then rejected at 0.05 level of significance.

\subsection{Hypothesis 2: There is no significant difference between students' religion and alcohol consumption.}

Table2: t-test showing alcohol consumption and students' religion

\begin{tabular}{|l|c|c|c|c|c|c|}
\hline Variable & $\mathrm{N}$ & MEAN & SD & Df & t-cal & t-crit \\
\hline Muslims & 71 & 53.0 & 127.0 & 138 & 2.23 & 2.02 \\
\hline Christains & 69 & 49.4 & 47.7 & & & \\
\hline
\end{tabular}

$P, 0.5$

Table2 shows that there is a significant difference between students' alcohol drinking and their religion. This shows that the t-cal is greater than the t-crit 2.02, thus we reject the null hypothesis. From the table, it is clear that students who are Muslims are highly exposed to alcoholic drinking because many believe it does not negate the ethics of their religion compared to students who have the mean of 49.4 as against that of muslim with the mean of

5.3 Hypothesis3: t-test showing alcohol consumption between students living with single parents and those living with both parents.

\begin{tabular}{|l|c|c|c|c|c|c|}
\hline Variables & $\mathrm{N}$ & Mean & $\mathrm{SD}$ & $\mathrm{Df}$ & $\mathrm{t}$-cal & $\mathrm{t}$-crit \\
\hline Students living with both parents & 35 & 19.0 & 11.8 & 138 & 7.86 & 2.02 \\
\hline Students living with single parents & 105 & 83.7 & 81.8 & & & \\
\hline
\end{tabular}

Table 3 shows that students living with both parents are less influenced by environmental factors compared to students living with single parents. The $\mathrm{t}$-cal value is greater than the t-tab at 0.05 level of significance; therefore, the null hypothesis is rejected.

\section{Discussion}

The result of the first hypothesis shows that the kind of families student came from had significant difference on their alcohol consumption. The reason for this can be traced to the fact the students from polygamous homes had no close 
monitoring compared to those from monogamous homes. This view is supported by Hirsch(1969) noted that young people who have strong bonding with their parents would interiorize the values and norms of their parents which results in behaving in a norm conforming way which most time is not readily available in polygamous homes. who argued that family background influences the response of youth to alcohol intake. Again, the findings from this research has shown that adolescents from single-parent households are more prone to delinquent behaviours, including drug and alcohol use this view is supported by the works of Amato and Keith (1991); Amey and Albrecht (1998); Barrett and Turner (2006).

\section{Conclusion}

The results of these findings reveal that one can conclude that the family from where one originates cannot be delineated from alcohol drinking. This is because variables that were found to be greatly significant to drinking were religion and family type.

\section{Recommendations}

Based on the findings of this study one can conclude that the bulk of the responsibility of curbing the menace of alcohol consumption among Nigerian secondary school students lies heavily on the home front. Again stringent policies should be greatly censored especially as regarding advertisement.

\section{References}

Amato, P.R.\& Keith B. (1991).Parental divorce and the well-being of children: a meta-analysis. Psychological Bulletin.110:26-46. [PubMed]

Adenuga, A.\& ljagbone, I.(2012).Correlates of Alcohol Consumption among Adolescents in Ibadan North Local Government Area of Oyo State, Nigeria. Mediterrean Journal of Social Sciences.Vol.3(2)May 2012

Amey, C.H., Albrecht, S.L.(1998). Race and ethnic differences in adolescent drug use: the impact of family structure and quantity and quality of parental interaction. Journal of Drug Issues. 1998;28:283-298.

Barrett, A.E., Turner, R.J.(2006). Family structure and substance use in adolescence and early adulthood: examining explanations for the relationship. Addiction.101:109-120. [PubMed]

Bennett, B. (1998). Mouse Genetic models in alcohol research: Trends Genetic; 22:367-374 (pub Med)

Hirschi, T. (1969). Causes of Delinquency, University of California Press, Berkeley, Calif, USA,

Johnson and Johnson (2000). Children beliefs about consequences of drinking and refusing to drink alcohol: Alcohol drug education 4:3:34- 43

Johnston LD, O'Malley PM, Bachman JG, Schulenberg JE. [Retrieved February 28, 2005];Overall teen drug use continues gradual decline: but use of inhalants rises. 2004 from www.monitoringthefuture.org.

WorldHealth Organization. (2004)Global Status report on Alcohol and Health Retrieved March 2, 2013 from http://www.who.int/substance_abuse/publications/en/zambia.pdf

Bennett, L.(1997). Substance abuse and women abuse by male partners, National Network on violence Against Women, September,pp1-8. Available:http://www.vawnet.org/Domesticviolence/Research/VAWnetDocs/ARsubstance.pdf [2012,23 March].

Quine, S.\& Stephenson, J.(1990). Predicting smoking and drinking intentions and behaviour of pre-adolescents: The influence of parents siblings and peers. Family System Medicine,8,pp. 191-201 
